
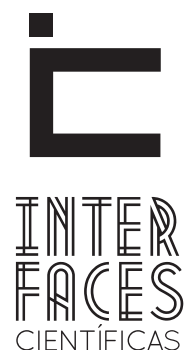

EDUCAÇÃO

ISSN IMPRESSO 2316-333X

ISSN ELETRÔNICO 2316-3828

\title{
PEDAGOGIA, PEDAGOGIA SOCIAL E EDUCAÇÃO SOCIAL NO BRASIL: ENTRECRUZAMENTOS, TENSÕES E POSSIBILIDADES
}

Érico Ribas Machado ${ }^{1}$

Marli de Fátima Rodrigues ${ }^{3}$
José Leonardo Rolim de Lima Severo²

\section{RESUMO}

Este texto introduz questões que começam a emergir na esteira do progressivo aparecimento da Pedagogia Social no discurso educacional brasileiro. Assinala possibilidades de entrecruzamento conceitual entre a Pedagogia e a Pedagogia Social, bem como tensões que dinamizam o debate sobre a formação de pedagogos e a regulamentação da profissão de educador social no cenário do Brasil. 0 debate que o configura se desdobra de modo a indicar algumas possibilida- des de compreensão do potencial da Pedagogia Social no contexto geral da teoria e da prática pedagógica, registrando uma abordagem crítica sobre aspectos formativos e político-institucionais associados ao trabalho educativo em diferentes espaços sociais.

\section{PALAVRAS-CHAVE}

Pedagogia. Pedagogia Social. Educação Social. 


\section{RESUMEN}

El artículo introduce cuestiones que están surgiendo a estera de la aparición gradual de la Pedagogía Social en el discurso educativo brasileño. Toma nota de las posibilidades de intersección conceptual entre la Pedagogía y la Pedagogía Social, así como tensiones que dinamizan el debate sobre la formación de pedagogos y la regulación de la profesión de educador social en el escenario de Brasil. El debate que se desarrolla está ajustado para indicar algunas posibilidades de comprensión del potencial de la Pedagogía Social en el contexto general de la teoría y la práctica pedagógica, registrando enfoque crítico de los aspectos formativos y político-institucionales relacionados con el trabajo educativo en diferentes espacios sociales.

\section{PALABRAS-CLAVE}

Pedagogía. Pedagogía Social. Educación Social.

\section{ABSTRACT}

This article introduces questions that are emerging in the wake of the gradual emergence of Social Pedagogy in Brazilian educational discourse. Register possibilities of conceptual intersection between Pedagogy and Social Pedagogy as well as tensions that moves the debate over the training of pedagogues and the professional regulation of social educator in the backdrop of Brazil. The debate realized indicates some possibilities for understanding the potential of Social Pedagogy in the general context of the theory and pedagogical practice, recording a critical approach to training and political-institutional aspects related to educational work in different social spaces.

\section{KEYWORDS}

Pedagogy. Social Pedagogy. Social Education. 


\section{INTRODUÇÃO: QUESTÕES E APONTAMENTOS INICIAIS}

O debate sobre a natureza da Pedagogia é uma ação recorrente no transcurso dos Séculos XX e XXI, tendo ocupado diferentes níveis de explicitação no interior de movimentos institucionais, teóricos e políticos no campo educacional. No Brasil, assim como em outros países, esse debate revela diferentes concepções epistemológicas em torno do objeto, do método e da natureza da Pedagogia que traçam seu perfil identitário como ciência, arte, tecnologia, ideologia ou norma da educação.

No final do Século XIX, pensadores alemães estabeleceram as bases de uma perspectiva pedagógica orientada aos processos socioeducativos que se articulavam mais fortemente a socialização cultural e a formação de identidades no âmbito da vida em sociedade. Nartop (apud PÉREZ SERRANO, 2003), personalidade expoente desse grupo de pensadores, tornou-se pioneiro em estabelecer os fundamentos de uma nova área denominada Pedagogia Social, termo que, mais tarde, após processo de sistematização conceitual, estruturação metodológica e formalização acadêmica, passou a designar o que hoje se conhece em alguns países como Teoria Geral da Educação Social.

Em que aspectos podemos vislumbrar possibilidades de entrecruzamento desses conceitos concernentes à realidade educativa? Que tensões conceituais, formativas e de ordem profissional se evidenciam a partir desses entrecruzamentos? Que contribuições são possíveis de serem extraídas desse debate para as práticas de formação e atuação de educadores, referenciando os desafios do contexto brasileiro? Para iniciarmos nossa reflexão com base nestes questionamentos problematizadores, convém explicitar alguns apontamentos iniciais.

Em primeiro lugar, considera-se que as relações entre os conceitos de Pedagogia e Pedagogia Social revitalizam a necessidade de exame das bases epis- temológicas do conhecimento educacional e como, a partir das mesmas, pode ser estabelecida uma matriz identitária para a Ciência da Educação e suas áreas constitutivas, as quais buscam contemplar diferentes dimensões, objetos, setores e formas de intervenção pedagógica no universo da educação como prática social complexa.

Outro apontamento correspondente ao escopo dos temas que este texto busca discutir, diz respeito ao processo de formação de pedagogos, em particular, e de educadores, em geral, pode ser conduzido para uma perspectiva mais ampla de educação, na qual se situa um projeto "ressignificado" de escola e de intervenções educativas não escolares pautadas por princípios da Pedagogia como Ciência da Educação e da Pedagogia Social.

É interessante, ainda, situarmos as relações temáticas propostas no plano das proposições de formação e regulamentação da profissão de pedagogos e demais educadores para a Educação Social, pensando em quais razões apontam para a importância de que se invista em um novo processo de profissionalização no país. Partindo disso, torna-se relevante pensar em que tensões aparecem como desafios políticos para fortalecer a identidade, a ação educativa e o reconhecimento social desses agentes da Pedagogia e da Pedagogia Social no contexto da realidade brasileira.

Esses apontamentos indicam possibilidades de reflexão sobre a introdução recente da Pedagogia Social no pensamento educacional brasileiro e de desdobramentos no campo da formação e da prática de pedagogos e educadores sociais. Sabemos que envolvem questões complexas e relevantes, provavelmente sem respostas absolutas e que demandam um esforço de problematização, crítica e proposição criativa.

Esse texto se propõe a destacar algumas dessas possibilidades reflexivas, registrando uma discussão inicial que se inscreve como colaboração ao debate ampliado sobre a Pedagogia Social no Brasil e suas conexões com a Pedagogia como âmbito de conhecimento, formação e prática profissional. 


\section{PEDAGOGIA E PEDAGOGIA SOCIAL: SITUANDO O DEBATE EM NÍVEL CONCEITUAL}

Neste tópico do texto nos ocuparemos em discutir as similitudes e especificidades conceituais da Pedagogia e da Pedagogia Social. Reconhecemos que estabelecer relações entre esses dois conceitos, se configura em um processo reflexivo que assume formas distintas e produz diferentes posicionamentos conforme o entendimento de base acerca do que consiste ser a Pedagogia e a Pedagogia Social.

Adotamos uma matriz de reconhecimento teórico que nos leva a conceituar a Pedagogia como Ciência da Educação e a Pedagogia Social como uma teoria geral da Educação Social. Tanto a Pedagogia quanto a Pedagogia Social se configuram como construtos conceituais com denso espectro de significados que variam em diversos aspectos, circunstância pela qual se torna relativa qualquer tentativa ou esforço teórico de construir um argumento de crítica relacional entre os mesmos.

Esclarecemos, assim, que as relações conceituais traçadas adquirem validade e pertinência no interior da reflexão baseada na matriz teórica anteriormente explicitada, ao mesmo tempo em que entendemos que afirmá-la requer um exame sócio-epistemológico de como as categorias conceituais se constroem enquanto discursos sociais e atuam como elementos que dinamizam o campo científico. Nesse sentido, a significação atribuída a esses conceitos, sua abrangência e correlações são determinadas por modos de compreensão que se associam a fatores sociais, históricos e geopolíticos.

Se tomarmos por base o contexto espanhol, por exemplo, a relação entre Pedagogia Social e Pedagogia se revelaria por meio de um entendimento diferente daquele que é possível vislumbrar no Brasil, país em que a Pedagogia Social, todavia, não se encontra estabelecida científica e academicamente, sendo a própria Pedagogia uma estância desde a qual são prescritas relações associativas com outras áreas de conhecimento de modo mais ou menos deliberado.

Na Espanha, país em que a Pedagogia Social está afirmada academicamente, gozando de estruturas acadêmicas consolidadas que lhe dão maior margem de maturidade e autonomia científica, as relações conceituais com a Pedagogia se mostram mais bilaterais. Isso quer dizer que a Pedagogia Social detém uma "voz científica" mais explícita que reclama para si a construção de um enfoque e objeto epistêmico autônomo. Contudo, essa realidade é fruto de um processo histórico peculiar daquele país, resultante, sobretudo, da maneira da qual a Pedagogia Social se estabeleceu como campo científico e repertoriou saberes e práticas profissionais.

Ao abordar a perspectiva da Sociologia Clínica do Campo Científico, Bourdieu (2004) aponta que a noção de campo científico designa um universo de produção e atividade social da ciência, organizada em comunidades institucionais situadas histórica e geograficamente, dinamizada por forças sociais e políticas internas e externas, e que funciona como um microcosmo que obedece a leis mais ou menos específicas. Bourdieu (2004, p. 21) infere que "[...] uma das grandes questões que surgirão a propósito dos campos (ou dos subcampos) científicos será precisamente acerca do grau de autonomia que usufurem".

Considerando a atual estruturação acadêmica da área de Educação no Brasil, a qual expressa, em maior ou menor medida, a incidência de um discurso científico legitimado na organização disciplinar da Pedagogia e de suas subdisciplinas, podemos reconhecer que a Pedagogia Social não constitui uma especialidade inscrita no seu âmbito. Essa circunstância não deriva de uma opção de recusa ou negação voluntária de pesquisadores brasileiros, mas parece estar associada a uma falta de tradição acadêmica que vincule os referenciais da Pedagogia Social como aportes de crítica e proposições na realidade educacional do país. 
De fato, o capital científico pertencente à Pedagogia Social, concebido como "[...] uma espécie particular de capital simbólico (o qual, sabe-se, é sempre fundado sobre atos de conhecimento e reconhecimento) que consiste no reconhecimento (ou no crédito) atribuído pelo conjunto de pares-concorrentes no interior do campo científico" (BOURDIEU, 2004, p. 26), representa um conjunto significativo de princípios teórico-metodológicos que auxiliam na construção de perspectivas conceituais e operativas da Pedagogia, a fim de a educação, como objeto epistêmico, seja compreendido e abordado em sua integralidade.

A Pedagogia Social atua, portanto, como uma matriz disciplinar que, partindo do pressuposto que reconhece o potencial que a pluralidade teórico-metodológica representa para os processos de produção de conhecimento pedagógico e, consequentemente, no aperfeiçoamento dos sistemas conceituais e tecnológicos que suportam as ações profissionais de educadores em diversos cenários socioeducativos, se inscreve no âmbito geral da Pedagogia, cuja especialidade recai em reflexões e práticas que enfatizam o caráter social e socializador da formação humana.

Nesse sentido, a relação entre Pedagogia e Pedagogia Social poderia ser descrita nos seguintes termos: a Pedagogia, como Ciência da Educação, abrange uma pluralidade de abordagens teóricas e metodológicas sobre aspectos da educação como objeto epistêmico, estando a Pedagogia Social imbricada na própria Pedagogia como uma teoria pedagógica que alimenta a práxis nos âmbitos da Educação Social. Por supor que o objeto da Pedagogia é a educação em sua totalidade como prática social (GHEDIN; FRANCO, 2008) e que o enfoque da Pedagogia Social alcança uma dimensão desse objeto sem constituir outro campo científico distinto - o que sustentaria uma posição reducionista do objeto epistêmico da Pedagogia e enfraqueceria o seu estatuto identitário - é que a definimos como um conjunto de teorias e métodos específicos que conformam uma disciplina autêntica da Ciência da Educação.
No seio da Ciência da Educação, se desenvolvem diferentes disciplinas científicas que aportam visões plurais do fenômeno educacional. A Pedagogia Social, como uma delas, se constitui como uma disciplina pedagógica e se caracteriza por aplicar um enfoque teórico-prático em problemáticas socioeducacionais. Luzuriaga (1961, p. 9), um autor clássico da tradição espanhola em Pedagogia Social adverte que "la pedagogia social no constituye uma disciplina o ciencia independiente sino que es sólo uma parte de la pedagogia general, como lo son la pedagogía individual o la tecnologica". A partir desse comentário, firma-se o caráter disciplinar da Pedagogia Social não como um corpo de conhecimentos e metodologias dissociado da Pedagogia Geral, esta última tida como âmbito no qual se inserem diferentes disciplinas que são integradas e articuladas com base nos princípios epistemológicos da Ciência da Educação.

O objeto da Pedagogia Social é a Educação Social, o qual define o conteúdo dessa disciplina: a relação da educação com a sociedade. Para desenvolver sistemas teórico-práticos que possam servir de referência para a gestão de práticas educativas nos contextos sociais, a Pedagogia Social conserva um duplo caráter, sendo este geral e específico. 0 caráter geral da Pedagogia Social se refere à metateoria que organiza e justifica a constituição de perspectivas conceituais e matrizes metodológicas para construção e validação do conhecimento que se identifica em seu âmbito. 0 caráter específico, por sua vez, designa as diferentes abordagens que, plasmando-se ao conceito geral de Pedagogia Social, priorizam distintos aspectos às problemáticas relativas aos sujeitos, contextos socioeducativos e formas de atuação dos educadores sociais.

Conformada por conhecimentos especializados construídos a partir da articulação entre investigação científica e a práxis dos pedagogos e educadores sociais, exercida em múltiplos contextos, a Pedagogia Social adquire peculiaridade entre as demais disciplinas pedagógicas e Ciências Humanas por abordar as problemáticas sociais sob o prisma educativo. 
As contribuições da Pedagogia Social à Pedagogia se mostram ainda mais relevantes quando se considera que a tradição acadêmica brasileira induziu os estudos pedagógicos a se centrarem com maior ênfase em processos instrucionais especialmente escolares. A ênfase no aspecto instrucional da educação restringiu o alcance teórico e metodológico da Pedagogia, a ponto de que seja comum associá-la a escola (SEVERO, 2012). Essa circunstância requer ser explorada à luz de uma contextualização histórica e institucional mais aprofundada, porém o escopo desse artigo não nos permite fazê-lo. Então, convém explicitar que entre os principais fatores que exerceram influência para que a mesma fosse constituída encontram-se a emergência da noção de Ciências da Educação que acabou que por produzir a fragmentação dos estudos no âmbito da Pedagogia e a redução do seu protagonismo científico no campo educacional; a incidência de perspectivas teóricas que concebem a Pedagogia como uma tecnologia educativa orientada principalmente para os processos instrumentais da educação; e a influência de posicionamentos políticos e ideológicos que afirmam a docência como base do desenvolvimento curricular no curso de Pedagogia.

Nesse cenário, a Pedagogia Social incita uma gama de reflexões que problematizam o sentido da formação e da prática pedagógica, expandindo as dimensões da educação para além do aspecto técnico, instrucional e escolar. 0 olhar da Pedagogia Social produz saberes e fundamenta competências que ampliam as possibilidades de crítica e proposição nos contextos da educação, reconhecendo a sua dimensão social em múltiplas conexões e enfatizando o potencial socializador da educação como razão para o enfrentamento de problemáticas sociais a partir da contribuição que os processos educativos podem oferecer.

A Pedagogia Social coloca em relevo questões sobre o papel da educação na sociedade contemporânea e realça as possibilidades de intervenção socioeducativa desde uma perspectiva pedagógica autêntica. É por esse viés que ela dialoga com o campo científico da Pedagogia no Brasil e possibilita referenciais para a construção de propostas de formação e prática pedagógica para além da docência escolar, embora suas contribuições teóricas e práticas também sejam pertinentes à tarefa da escola, considerando o objetivo da socialização em contextos formativos cada vez mais complexos e dinâmicos que desafiam a perspectiva tradicional de ensino unicamente preocupado com o desenvolvimento de competências cognitivas baseadas no domínio de saberes disciplinares.

\section{A PEDAGOGIA NO BRASIL: PROBLEMATIZAÇ̃̃O DE ASPECTOS FORMATIVOS}

A discussão até aqui nos mostra a necessidade emergente de se pensar a formação de um profissional que toma como referência os processos educativos em sua dimensão de totalidade, particularmente nos momentos em que a dinamicidade das relações sociais e produtivas exige a formulação, no plano coletivo, de novas propostas de formação humana, para as quais não temos percursos formadores.

A definição do papel e dos desafios da Pedagogia, enquanto área de conhecimento, bem como, a falta de clareza ao diferenciar concepção de pedagogia e concepção de curso tem sido o principal obstáculo para o avanço das discussões na área, haja vista que na definição das atuais Diretrizes Curriculares Nacionais para os Cursos de Pedagogia (DCNs) (BRASIL, 2006), ao invés da flexibilidade apresentada pela legislação para que as instituições experimentem novas possibilidades e percursos pedagógicos, adota-se um percurso curricular que privilegia a docência na Educação Infantil e Anos Iniciais do Ensino Fundamental. Tal proposta, além de desconsiderar a pedagogia como área específica de conhecimento, desvaloriza a pedagogia que está posta nas relações sociais e noutras dimensões e processos pedagógicos, também importantes.

As decisões contidas nas atuais DCNs para os cursos de Pedagogia resultaram na redução do campo 
epistemológico da Pedagogia, com seu vasto elenco de possibilidades formativas que não se limitam apenas a uma dimensão tecnológica de preparação técnica para o exercício do magistério da educação básica.

A compreensão que determina que os estudos em educação se iniciem, necessariamente, pela formação e prática na docência da educação básica como pré-requisito para a formação do pedagogo, contradiz as novas demandas do mundo do trabalho, que abrem inúmeras possibilidades de atuação em diferentes espaços formativos. Não obstante, o perfil e as competências atribuídas ao Pedagogo, além de muito ampliadas, dizem respeito predominantemente a dimensões práticas da ação educativa e ao domínio dos conhecimentos escolares, com o que certamente se fragiliza ainda mais a formação docente.

Muito embora a concepção de ação docente definida nas DCNs passou a abranger, também, a participação na organização e gestão de sistemas e instituições de ensino e a produção e difusão do conhecimento científico-tecnológico do campo educacional em contextos escolares e não escolares, consideramos que estas áreas de formação e atuação demandam ações que não podem ser reduzidas à docência.

O Curso de Pedagogia, com a definição de suas diretrizes, passa a ser entendido como espaço de profissionalização estreita (KUENZER; RODRIGUES, 2011). Desconstruir essa perspectiva reducionista requer o entendimento que este curso é o espaço que as Universidades e Faculdades de Educação dispõem para os estudos sistemáticos e avançados na área da Educação, o que requer entender a Pedagogia como ciência e enfrentar seriamente o debate em torno de seu estatuto epistemológico.

Ressignificar o papel do Pedagogo é urgente, pois este profissional vem sofrendo pesadas críticas pela formação fragmentada, superficial e inconsistente que não garante o necessário referencial para atuação docente. De outra parte, insistir numa atitude in- gênua e idealista que coloca o Pedagogo como "faz tudo" tem contribuído para a descaracterização e desqualificação deste profissional.

Dessa forma, consideramos que tais políticas de formação contrariam os avanços alcançados nas últimas décadas sobre a pesquisa e o debate acerca da Pedagogia e de seu estatuto epistemológico, principalmente considerando a relevância do seu papel social na construção de uma sociedade pautada na justiça social, na solidariedade, no respeito à diversidade, na liberdade e na igualdade de direitos. Cabe considerar aqui a necessidade de se rever as DCNs para o curso de Pedagogia, desenvolvendo uma reflexão epistemológica que supere os limites estreitos de uma proposta que fragiliza a formação de professores e o próprio campo da Pedagogia, retirando a dimensão da ciência e a reduzindo a uma dimensão "tarefeira”.

Enfim, são muitas as possibilidades de atuação deste profissional colocadas na atualidade, por isso defendemos que a Pedagogia é mais do que um percurso de docência. No entanto, a problemática que envolve a questão da identidade epistemológica da Pedagogia enquanto campo de conhecimento e de investigação marca o percurso histórico desse curso e, de certa forma, tem impedido que se defina um percurso curricular para a formação do pedagogo não-escolar.

\section{APONTAMENTOS PARA A FORMAÇÃO DO PROFISSIONAL EDUCADOR SOCIAL NO BRASIL}

A partir do início dos anos dois mil, intensificou-se o movimento pela divulgação, fundamentação e estruturação da Pedagogia Social no Brasil, área já estruturada em outros países, mas que assume peculiaridades na sua organização devido à cultura e à história de cada realidade. Considerando esse aspecto, torna-se necessário acessar conteúdos históricos e culturais para compreender cada contexto. 
No percurso histórico da educação brasileira identificam-se práticas educativas circunscritas em contextos de grupos humanos diferenciados. Acredita-se que muitas dessas práticas já foram referenciadas e identificadas dentro dos campos de pesquisa das áreas da Educação Popular, Educação Não-Formal, entre outras, mas existe grande possibilidade de que existam mais vivências educativas que ficaram fora dos relatos históricos das pesquisas publicadas.

O fato é que o desenvolvimento dessas práticas educativas, que vai além da perspectiva de transmissão de conteúdos escolares, culminam na existência de uma gama de processos de construção de conhecimentos nos mais diversos ambientes sociais com diferentes metodologias e estratégias de relações entre os sujeitos envolvidos.

A contribuição significativa que a Educação Popular traz para essa discussão torna-se fundamental quando se considera que práticas educativas populares surgem a partir das práticas culturais de cada grupo humano. 0 acúmulo das produções científicas da área permite conhecer a fundo as relações educativas próprias do sujeito brasileiro. Algo próximo das discussões antropológicas que podemos identificar com as contribuições das pesquisas desenvolvidas no âmbito da Educação Não-Formal, em que se consideram as relações educativas presentes nas relações entre os sujeitos com suas diferenças culturais.

Essas considerações introduzem, brevemente, reflexões sobre como as práticas educativas em diferentes contextos estão sendo consideradas atualmente. Brandão (2002) e Streck (2006), importantes pesquisadores da Educação Popular, apontam em suas reflexões mudanças significativas de como a área vem se apresentando recentemente, o que converge com os argumentos de Ribas Machado (2010) quando busca estabelecer as relações com a Pedagogia Social, considerando aspectos históricos do uso de suas terminologias no Brasil, dos seus fundamentos, como também dos temas inscritos nas pesquisas das áreas. Já, a tradicional separação para compreensão do contexto educativo do país, em Educação Formal, Informal e Não formal não condizem mais com o contexto real, considerando os aspectos das práticas, dos fundamentos, e das políticas para a educação brasileira. 0 limite entre uma definição e outra nunca esteve tão complexo de ser identificado, talvez, devido às mudanças da sociedade contemporânea.

Quando se considera a escola como instituição única dos processos educativos reconhecidos socialmente, economicamente e juridicamente, se defende que o profissional que irá atuar nesse espaço seja alguém com formação e que atenda a legislação específica. Com a Pedagogia Social surge a necessidade de se reconhecer que em outros espaços sociais, também, ocorrem processos educativos e que por isso é necessário que esse reconhecimento demande uma política específica que oriente essa complexa área.

Com o contexto descrito, o momento atual demanda um aprofundamento dos debates sobre a necessidade de formação e regulamentação do profissional da Pedagogia Social, que é o Educador Social.

Para refletir sobre essas questões, é importante retomar as considerações já realizadas neste texto, de que se compreende a Pedagogia Social como uma teoria pedagógica, ou seja, é dentro da complexa área da Pedagogia que a formação do profissional deverá ocorrer. Essa perspectiva corrobora com os argumentos de Úcar (2013) em que se apresenta a Pedagogia como um puzzle - quebra-cabeça, descrevendo a complexa relação entre os processos de ensino e aprendizagem que envolve aspectos biológicos e socioculturais dos seus sujeitos participantes, por isso a importância de considerar os argumentos que introduzem esse tópico do texto.

É justamente a questão sobre os quais os níveis, em quais cursos e quem deverão ofertar a formação do profissional da Pedagogia Social, um dos aspetos mais polêmicos e divergentes do processo do tramite do Projeto de Lei $n^{0} 5346$, que tramita desde 2009 e que prevê a regulamentação da profissão do Educador Social. 
Este projeto pretende oficializar uma área profissional, reconhecendo sujeitos que atuam nos mais diferentes espaços educativos junto a pessoas de todas as faixas etárias. A amplitude dos âmbitos de atuação, bem como a diversidade de trabalhadores que por meio de diversas nomenclaturas e formações, tornam uma conclusão demasiadamente complexa. São trabalhadores concursados ou contratados, alguns sem nenhum nível de escolaridade, outros com o ensino superior completo e até mesmo com pós-graduação em todas as áreas possíveis, exercendo funções educativas atendendo suas demandas, sem estar articulado a uma perspectiva mais ampla de regulamentação e fundamentação.

Úcar (2014) considera que a formação do Educador Social deve contemplar três aspectos principais: a) conhecimento das ferramentas metodológicas e técnicas básicas para o seu trabalho dentro do setor da Educação Social; b) condições para analisar situações socioeducativas complexas e direcionar as devidas respostas; c) condições para aprender com sua prática, construindo um repertório próprio de atuação profissional.

Essas considerações de Úcar nos faz refletir que o profissional dessa área requer um curso de formação inicial que tenha um currículo específico que atenda essa complexa área da Educação Social, em que a Pedagogia Social aparece como a disciplina própria da área, abordando os aspectos históricos e de fundamentos, mas que seja articulado à realidade prática da atuação profissional. Esse aspecto entendido como práxis é fundamental quando em outras realidades já se admite que tal distanciamento que prejudica o trabalho socioeducativo, como bem argumenta Storo (2012) referindo-se a países onde a área já está estruturada há mais tempo.

Alguns debates brasileiros apontam para a necessidade de criação de um curso de graduação específico em Pedagogia Social para contemplar essas questões, outros posicionamentos acreditam que esse curso receba a nomenclatura de Educação Social. Há, ainda, os que defendem que essa formação aconteça no interior dos cursos de Pedagogia com a criação de um eixo curricular próprio voltado às especificidades da Educação Social.

O fato é que ainda é incipiente o debate tanto do meio acadêmico como no meio dos sujeitos que atuam como Educadores Sociais para que se chegue a uma política nacional de formação e reconhecimento profissional, a qual começa a se estruturar no Brasil a partir de alguns projetos em tramitação nas instâncias do poder legislativo. Devido às diferenças culturais, oriundas das desigualdades sociais, do tamanho geográfico do nosso país e outras questões, é imprescindível que a articulação para a formulação e definição de políticas em nível nacional seja efetiva e, que especialmente envolva todas as bases representativas possíveis.

\section{REFLEXÕES FINAIS}

As questões que buscamos discutir ao longo do texto revelam um horizonte de reflexões complexas e que precisam ser inseridas numa agenda mais ampla de debates, envolvendo pesquisadores e profissionais que se dedicam ao campo da educação em suas mais variadas manifestações. Trata-se de uma discussão que necessita se desenvolver no âmbito epistemológico, formativo e político-institucional.

Defendemos que é preciso que o debate seja entendido como um mecanismo de construção de possibilidades a serem assumidas pelas instituições e sujeitos que atuam no campo das práticas educativas e sirva de referência para que o diálogo entre Pedagogia e Pedagogia Social seja potencializado no Brasil, contribuindo para o reconhecimento e valorização da Educação Social como âmbito de atuação profissional.

A Pedagogia Social, articulada às bases da própria Pedagogia, pode se configurar como um importante recurso teórico-metodológico para fortalecer o eixo de formação de pedagogos não escolares, especialmente. Como fundamento de uma profissão específica, a Pedagogia Social se aplica por meio da ação dos Educadores 
Sociais que intervêm de modo a desenvolver competências sociais em diversos âmbitos de atuação, cuja regulamentação profissional consiste num importante avanço para colaborar com o protagonismo da área.

\section{REFERÊNCIAS}

BOURDIEU, Pierre. Os usos sociais da ciência: por uma sociologia clínica do campo científico. São Paulo: UNESP, 2004.

BRANDÃO, Carlos Rodrigues. A educação popular na escola cidadã. Petrópolis: Vozes, 2002.

GHEDIN, Evandro. FRANCO, Maria Amélia Santoro. Questões de método na construção da pesquisa em educação. São Paulo: Cortez, 2008.

LUZURIAGA, Lorenzo. Pedagogía social y política. Buenos Aires: Losada, 1961.

PÉREZ SERRANO, G. Pedagogía social - educación social. Construcción científica e intervención práctica. Madrid: Narcea, S.A. de Ediciones, 2003.

RIBAS MACHADO, Érico. A Constituição da Pedagogia Social na realidade educacional brasileira. Dissertação (Mestrado) - Universidade Federal de Santa Catarina, Florianópolis, 2010.

RODRIGUES, Marli de F.; KUENZER, Acácia Z. Revista Olhar de Professor. Ponta Grossa, 10(1): 35-62, 2007.

Recebido em: 1 de junho de 2014 Avaliado em: 22 de junho de 2014 Aceito em: 7 de agosto de 2014
RODRIGUES, Marli de F. Curso de Pedagogia: Epistemologia e Currículo. Publicatio UEPG Ciências Humanas, Ponta Grossa, 19 (2): 141-149, jul/dez. 2011.

RODRIGUES, Marli de F.; KUENZER, Acácia Z Curso de Pedagogia ou Curso Normal Superior? Revista Brasileira de Política e Administração da Educação v.23, n.2, p.253-275, mai/ago, 2007.

SEVERO, José Leonardo R. de L. A constituição da pedagogia: entre a instrucionalização e o paradigma da ciência da educação. Revista Temas em Educação, v.20/21, n.1, 2012.

STORO, Jan. The Difficult Connection between Theory and Practice in Social Pedagogy. International Journal of Social Pedagogy, v.1, n.1, 2012.

STRECK, Danilo. R. A educação popular e a (re) construção do público. Há fogo sob as brasas? In: Revista Brasileira de Educação. v.11, n.32. Rio de Janeiro, Mai/Ago. 2006.

ÚCAR, Xavier. La pedagogía como puzzle. In: Jornal A página da Educação. Invierno, 2013, p.24-26.

ÚCAR, Xavier. Formación inicial y permanente en Educación Social. Métodos y herramientas de investigación e intervención: aportación para el debate. Revista de Educación Social, n. 18. 2014. 